\title{
Does Cold Water or Ice Slurry Ingestion During Exercise Elicit a Net Body Cooling Effect in the Heat?
}

\author{
Ollie Jay $^{1,2} \cdot$ Nathan B. Morris ${ }^{1}$
}

Published online: 24 January 2018

(C) The Author(s) 2018. This article is an open access publication

\begin{abstract}
Cold water or ice slurry ingestion during exercise seems to be an effective and practical means to improve endurance exercise performance in the heat. However, transient reductions in sweating appear to decrease the potential for evaporative heat loss from the skin by a magnitude that at least negates the additional internal heat loss as a cold ingested fluid warms up to equilibrate with body temperature; thus explaining equivalent core temperatures during exercise at a fixed heat production irrespective of the ingested fluid temperature. Internal heat transfer with cold fluid/ice is always $100 \%$ efficient; therefore, when a decrement occurs in the efficiency that sweat evaporates from the skin surface (i.e. sweating efficiency), a net cooling effect should begin to develop. Using established relationships between activity, climate and sweating efficiency, the boundary conditions beyond which cold ingested fluids are beneficial in terms of increasing net heat loss can be calculated. These conditions are warmer and more humid for cycling relative to running by virtue of the greater skin surface airflow, which promotes evaporation, for a given metabolic heat production and thus sweat rate. Within these boundary conditions, athletes should ingest fluids at the temperature they find most palatable, which likely varies from athlete to athlete, and therefore best maintain hydration status. The cooling benefits of cold fluid/ice ingestion during exercise are
\end{abstract}

Ollie Jay

ollie.jay@sydney.edu.au

1 Thermal Ergonomics Laboratory, Exercise and Sport Science, Faculty of Health Sciences, University of Sydney, 75 East St., Sydney, NSW 2141, Australia

2 Charles Perkins Centre, University of Sydney, Sydney, NSW, Australia likely disproportionately greater for athletes with physiological disruptions to sweating, such as those with a spinal cord injury or burn injuries, as their capacity for skin surface evaporative heat loss is much lower; however, more research examining these groups is needed.

\section{Introduction}

During prolonged aerobic exercise, metabolic rate rises substantially from rest to provide the body with the energy needed to perform large amounts of muscular work [1]. Subsequently, the vast majority ( $>70$ to $75 \%$ ) of metabolic energy is liberated as heat and must be dissipated from the skin to the surrounding environment to maintain internal body (core) temperature within optimal limits [2]. Ultimately, if skin surface heat loss, which is physiologically mediated by sweating and cutaneous vasodilation responses but also greatly dependent upon environmental conditions, is insufficient, the prevailing large elevations in core and skin temperature contribute to profound decrements in endurance sports performance [3]. For example, time to exhaustion during exercise at a fixed intensity can be more than halved at an ambient air temperature of $31{ }^{\circ} \mathrm{C} \mathrm{com}$ pared with $11^{\circ} \mathrm{C}$ [4], while self-paced marathon completion time increases by $\sim 12 \%$ at a wet bulb globe temperature of $25{ }^{\circ} \mathrm{C}$ relative to $10{ }^{\circ} \mathrm{C}$ [5].

In an attempt to mitigate heat-related impairments in aerobic exercise, performance athletes and sports practitioners regularly employ different cooling strategies both before (pre-cooling) and during (mid-cooling) exercise $[6,7]$. Research has shown that pre-cooling athletes, using cold water immersion $\left(2-20{ }^{\circ} \mathrm{C}\right)[8,9]$, ice vests applied to the torso [10] or neck cooling collars $[11,12]$ blunts heatrelated decrements in performance [7]. While likely beneficial, most of these interventions are not particularly 
feasible in low-resource environments (such as awaygames, competition in remote areas and amateur sport) and have limited application as a cooling strategy during exercise, especially competition. Arguably, the most practical cooling solution is the ingestion of cold water or an ice slurry (cold water mixed with crushed ice) before and/or during exercise.

The evidence supporting the efficacy of ice slurry or cold $\left(<10{ }^{\circ} \mathrm{C}\right)$ water ingestion for improving endurance exercise performance in the heat when employed as a precooling [13-21], mid-cooling [22-28] or recovery between bouts $[29,30]$ strategy has been comprehensively reported. However, whether these strategies actually reduce the amount of heat stored inside the body during exercise in the heat, even at a fixed metabolic rate, is currently unclear. The underlying rationale for using cold water or ice slurry ingestion is that additional internal heat transfer is introduced as the ingested bolus heats up to equilibrate with internal body temperature. The total amount of heat transfer is dependent upon the temperature difference between the ingested fluid and the body, the specific heat capacity of the fluid $\left(4.186 \mathrm{~kJ} \cdot \mathrm{kg}^{-1} \cdot{ }^{\circ} \mathrm{C}^{-1}\right.$ for water $)$ and the volume/mass ingested. Moreover, the ingestion of an ice slurry mixture induces even more heat transfer owing to the enthalpy of fusion of ice $(334 \mathrm{~kJ} / \mathrm{kg})$. Nevertheless, this internal heat transfer occurs as part of a dynamic system of whole-body heat balance that is profoundly altered by physiological responses (primarily sweating) and the characteristics of the environment that envelops the athlete (i.e. air temperature, humidity, wind speed and radiant heat load). As such, how successfully cold water or ice slurry ingestion ultimately impacts whole-body heat content during exercise in the heat is greatly dependent on the parallel sweating response and the prevailing environmental conditions.

The aims of this review are to (1) describe the physiological and biophysical factors determining whether a cold fluid or ice slurry ingestion results in a net cooling effect from a human heat balance perspective; and (2) identify the boundary environmental conditions at which cold fluid or ice slurry ingestion should be recommended as an effective strategy for reducing body heat content during exercise.

\section{Fundamentals of Human Heat Balance during Athletic Competition}

The extent to which an athlete's body temperature changes during exercise is determined by (1) the net difference between internal heat generation and skin surface heat dissipation (body heat storage), (2) body mass and (3) specific heat capacity of the body's tissues [2]. As the body mass and specific heat capacity of an athlete do not change dramatically across the course of a typical sporting event (except in extreme cases, e.g. Marathon des Sables [31]), cooling interventions can solely serve to alter an athlete's body temperature by modifying body heat storage, which is classically described using the conceptual human heat balance equation [32]:

$S=(M-W) \pm K \pm C \pm R-E$.

Metabolic heat production is determined by metabolic energy expenditure $(M)$ minus the amount of external work $(W)$ that is concomitantly produced. Metabolic energy expenditure is directly governed by the athlete's absolute rate of oxygen consumption $\left(V \mathrm{O}_{2}\right.$; in $\left.\mathrm{L} \cdot \mathrm{min}^{-1}\right)$, and the proportion of this oxygen that is used to catabolise carbohydrates (yielding $21.13 \mathrm{~kJ}$ of energy per $1 \mathrm{~L}$ of $\mathrm{O}_{2}$ consumed) relative to fats (yielding $19.69 \mathrm{~kJ}$ of energy per 1 $\mathrm{L}$ of $\mathrm{O}_{2}$ consumed). The rate of external work performed on a bicycle is chiefly determined by pedalling speed, and the external resistance that must be overcome, which itself is modified by the weight of the rider, the gradient and the type of terrain. Because of continuous friction between tyres and the ground, external work must still be performed even when cycling on a flat surface. Running on a flat surface in contrast results in a negligible amount of external work as the propulsion and breaking forces of gait result in equal amounts of positive and negative work, respectively $[33,34]$. The amount of external work performed by running up a hill is solely determined by the vertical displacement of the athlete [34], but remains relatively small $(<5 \%$ of $\mathrm{M})$ compared with cycling ( 20 to $25 \%$ of M).

The net rate of heat loss from the skin surface to the surrounding environment is the sum of heat exchange via conduction $(K)$, convection $(C)$, radiation $(R)$ and evaporation $(E)$. Conduction, which is heat transfer through direct contact with a solid surface, is generally considered negligible for most exercise scenarios [35]. For a runner, as an example, the only direct physical contact with a solid surface occurs between the soles of the feet, which have a relatively small contact area and are usually insulated by shoes, and the ground.

Convective heat exchange is accelerated by the flow of air moving across the skin surface, which can arise from environmental air movement and/or self-generated air movement as an athlete propels themselves through an air mass. Convection is also directly dependent upon the temperature difference between the skin and the ambient environment. When air temperature is equal to skin temperature $\left(\sim 33\right.$ to $\left.35^{\circ} \mathrm{C}\right)$, no convective heat exchange occurs irrespective of air velocity. At even warmer air temperatures $\left(>35^{\circ} \mathrm{C}\right)$, convective heat loss becomes convective heat gain, that is, dry heat is added to (as opposed to removed from) the body, which is further accelerated with higher air velocities [36, 37]. This 
phenomenon is analogous to the faster cooking time of food in a fan-assisted oven compared with a conventional oven. It is also worth noting that additional convective heat exchange also occurs via respiration but in terms of wholebody heat exchange the contribution is relatively small, especially in warm environments [38].

Radiative heat exchange is electromagnetic energy transfer between a relatively warm and cool body. Similarly to convection, $R$ is driven by the temperature gradient between the skin and the environment, however, in this case mean radiant temperature-determined using black globe temperature and air velocity-is the important environmental parameter. In hot and particularly sunny climates, thermal radiation is added to the body as a result of the higher mean radiant temperature relative to skin temperature. The greatest source of thermal radiation in most sports-related settings is almost always solar radiation. Depending on the time of day, season, cloud cover and latitude, black globe temperature can be as much as $\sim 15^{\circ} \mathrm{C}$ higher than ambient air temperature. For example, on a hot and sunny midsummer day in Sydney, Australia, black globe temperature at $1 \mathrm{pm}$ can be as high as $50{ }^{\circ} \mathrm{C}$ when ambient air temperature (measured in the shade) is $\sim 35^{\circ} \mathrm{C}$ [39]. The posture and orientation of the athlete relative to the sun, which determine the effective radiative area of the body, will also substantially contribute to the amount of thermal radiation absorbed by the body [35].

In humans, heat loss by evaporation occurs as a result of a difference in humidity between the skin surface, which is physiologically moistened by eccrine sweating, and ambient air. It is worth emphasising that absolute humidity is the critical environmental factor influencing evaporation, and not relative humidity $(\mathrm{RH})$, which is the most commonly provided metric in meteorological reports. Absolute humidity at a fixed $\mathrm{RH}$ increases exponentially with ambient temperature, described by Antoine's equation [35], to the extent that twice the amount of moisture is present at $30 \% \mathrm{RH} / 38{ }^{\circ} \mathrm{C}$ than at $30 \% \mathrm{RH} / 26^{\circ} \mathrm{C}$. Similarly, absolute humidity is higher at $30 \% \mathrm{RH} / 40{ }^{\circ} \mathrm{C}$ than at $50 \% \mathrm{RH} / 30{ }^{\circ} \mathrm{C}$. In circumstances where all sweat does not readily evaporate and residual sweat sits on the skin (e.g. exercise coupled with high humidity), sweat evaporation is also heavily influenced by airflow across the skin surface. That is, evaporative heat loss is much higher in a hot, dry and windy environment compared with a hot, humid and still environment.

Humans have an upper limit for evaporative heat loss $\left(E_{\max }\right)$ that is determined by different characteristics depending upon the type of environment. In hot but very dry environments, $E_{\max }$ is capped by the physiological capacity to secrete sweat [3]; but in more humid environments, $E_{\max }$ is determined by the maximum proportion of total body surface area that can be completely covered with sweat, i.e. maximum 'skin wettedness' $\left(\omega_{\max }\right)$ [40]. Values for $\omega_{\max }$ range from 1.00 , which indicates that the entire body surface area is completely covered with sweat and is only observed in fully heat-acclimated athletes [41], through to $0.80-0.85$ in non-heat-acclimated persons [41].

Recent data [42] from our laboratory indicate that the partial heat acclimation associated with 8 weeks of aerobic training in a temperate environment leads to $\omega_{\max }$ values of $\sim 0.90$ to 0.95 . However, $\omega_{\max }$ values in athletes with injuries that have greatly altered regional sweat gland function, e.g. spinal cord-injured athletes or athletes with burn injuries, will only be able to achieve much lower wholebody $\omega_{\max }$ values, depending on the extent of injury (e.g. size and region of area burned; level and completeness of spinal cord injury). However local skin wettedness on the skin areas that can sweat will reach higher values for a given wholebody sweat rate. Irrespective of acclimation or training status, as skin wettedness increases towards its maximum value, sweating efficiency, i.e. the amount of sweat that evaporates relative to the amount of sweat produced, drastically decreases [43]. Sweating efficiency is an important notion because it is the evaporation of sweat that liberates heat from the body ( $2430 \mathrm{~J}$ of latent heat for every $1 \mathrm{~g}$ of sweat vaporised [35]) and not the production of sweat. It follows that under conditions that yield a low sweating efficiency, a reduction in sweat rate may not necessarily impact evaporative heat loss from the skin if that sweat would otherwise just remain on the skin or drip off the body.

The change in body heat storage $(S)$ during exercise is determined by the cumulative difference in metabolic heat production $(M-W)$ and net heat dissipation from skin to the surrounding environment $( \pm K \pm C \pm R \pm E)$ [32]. During exercise at a fixed intensity (and thus $M-W$ ), which requires a fixed rate of net heat dissipation to achieve heat balance as described in Eq. 1, the amount of evaporative heat loss $(E)$ required increases as the amount of dry heat loss $(K+C+R)$ decreases with a progressively warmer environment (Fig. 1). The rate of whole-body sweating required to achieve the required rate of evaporation is altered by sweating efficiency, which itself is determined at a fixed exercise intensity by a combination of ambient humidity and air flow across the skin of the athlete (Fig. 1). When ambient air temperature exceeds skin temperature, which is typically $\sim 35^{\circ} \mathrm{C}$, all skin surface heat dissipation must occur via the evaporation of sweat. It follows that in a hot, still and humid environment, an athlete is unable to physiologically compensate metabolic heat production with sufficient evaporation. Indeed, under such conditions additional sweat secretion does not serve to enhance heat loss as it is destined to simply drip off the body and not contribute to evaporation [41]. The subsequent development of 'uncompensable' heat stress, which is most prominently characterised by a sustained rate of rise in core (and usually skin) temperatures [44] owing to a 
Fig. 1 Changes in dry heat loss $[\mathrm{DHL}=$ conduction

$(K)+$ convection

$(C)+$ radiation $(R)]$ and the required evaporation (EVAP) to achieve a total heat loss (total HL) of $700 \mathrm{~W}$ with increasing air temperature under still [air velocity $(v): 0.5 \mathrm{~m} \cdot \mathrm{s}^{-1}$ ] and windy $\left(v: 5.0 \mathrm{~m} \cdot \mathrm{s}^{-1}\right)$ conditions and no solar load (a). Parallel whole-body sweat rates required to achieve the levels of EVAP depicted in (a) are shown in (b) for dry [relative humidity (RH) 25\%] and humid (RH $60 \%$ ) conditions

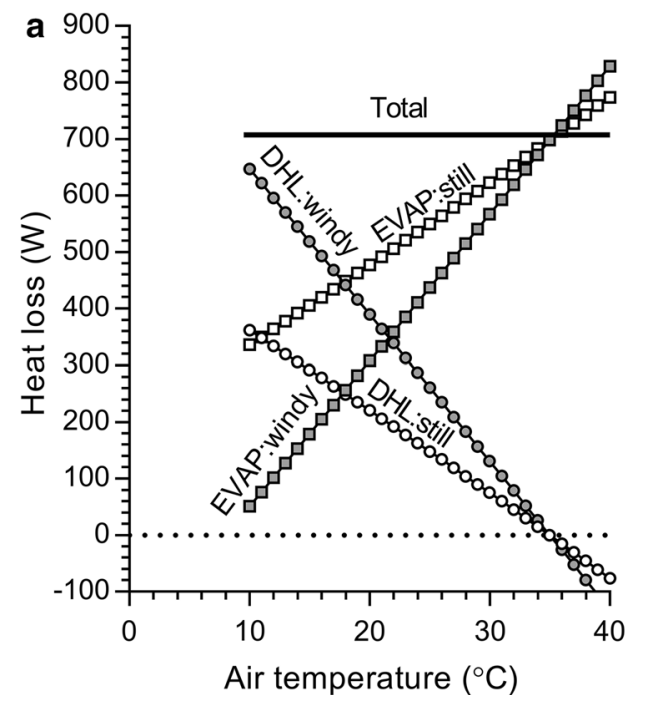

continuous rate of heat accumulation inside the body, greatly increases the risk of heat-related illness and injury for an athlete [45].

\section{How Does Cold Fluid or Ice Slurry Ingestion Impact Human Heat Balance?}

Cold fluid ingestion introduces a new avenue of heat transfer (internal heat transfer) for an athlete exercising in the heat in addition to the four avenues of heat transfer at the skin surface $[14,25,46]$. Body heat storage with cold fluid ingestion is therefore determined by the cumulative difference between metabolic heat production and the combined heat loss from the skin surface and any internal heat transfer with an ingested fluid (Fig. 2). It stands to reason that if net heat dissipation from the skin remains unaltered with cold fluid ingestion, body heat storage will be lower and the athlete will likely be at a lower risk of heat-related illness. Given that most skin surface heat loss during exercise in hot climates must occur via evaporation, any physiological modifications of sweating with cold fluid ingestion will have the greatest impact on heat balance. Moreover, if any reductions in skin blood flow also occur with cold fluid ingestion, then any consequent changes in skin temperature may also modify the rate of dry heat loss via convection and radiation occurring at the skin surface. Ultimately, if eccrine sweating and skin blood flow are reduced with cold fluid ingestion to the extent that skin surface evaporation and dry heat loss are lowered in proportion to the internal heat transfer taking place mostly inside the stomach, then combined heat loss (i.e. skin surface + internal) may not be enhanced relative to the ingestion of a thermoneutral fluid.

\subsection{Modifications of Physiological Heat Loss Responses with Cold Fluid/Ice Slurry Ingestion during Exercise and Their Impact on Heat Balance}

The influence of cold fluid ingestion on sweating and heat balance was first described in resting individuals in a 1942
Fig. 2 Determinants of body heat storage with cold fluid ingestion during exercise

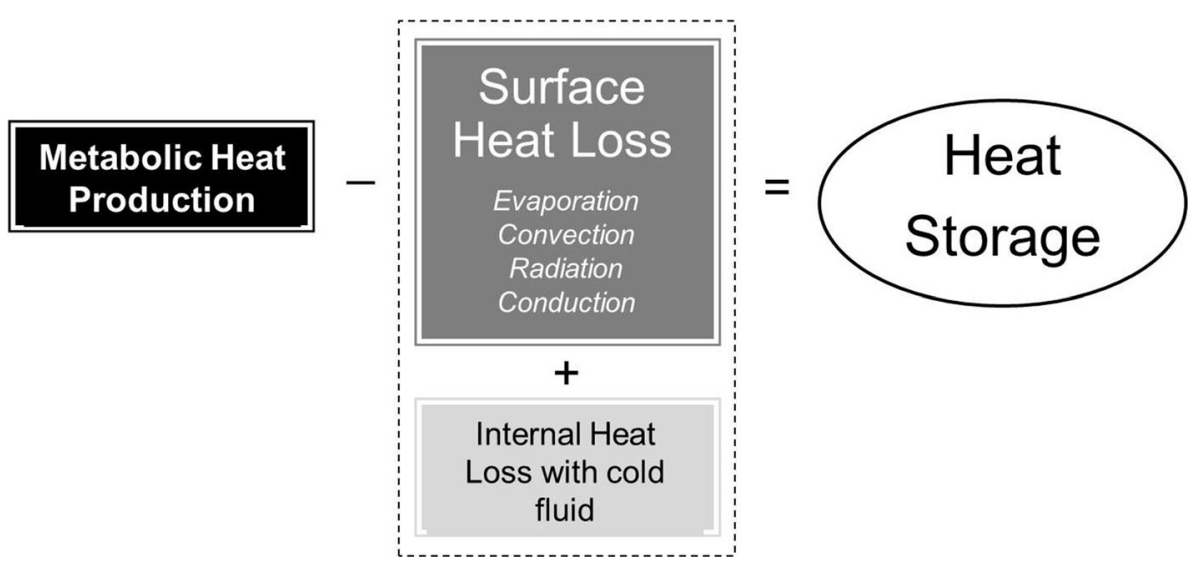


study by Pinson and Adolph [47]. They reported that ingestion of $1.4-1.7 \mathrm{~L}$ of $1-3{ }^{\circ} \mathrm{C}$ water at rest in a $31{ }^{\circ} \mathrm{C}$ and $20-30 \%$ RH room led to a $\sim 50 \%$ decrease in evaporative heat loss from the skin, with losses remaining depressed for $3 \mathrm{~h}$ post-ingestion. Through partitional calorimetry they reported that $200 \mathrm{~min}$ after ingestion, $85 \%$ of the internal heat loss to the ingested fluid had been regained; half by decreases in skin surface evaporation and half by decreases in dry heat loss via convection, suggesting an effect of cold fluids on both sweating and vasodilation. Later, Nadel and colleagues [48] characterised the effect of ingesting two different masses of ice cream (518 and $260 \mathrm{~g}$ ) and different temperatures of hot pudding $\left(37^{\circ} \mathrm{C}\right.$ and $\left.55-60{ }^{\circ} \mathrm{C}\right)$ in participants sitting in environments ranging from 10 to $44{ }^{\circ} \mathrm{C}$. In the coolest condition $\left(10^{\circ} \mathrm{C}\right)$, ice cream ingestion caused a marked increase in metabolic heat production and thus shivering thermogenesis, whereas in the hottest condition $\left(44^{\circ} \mathrm{C}\right)$, ice cream ingestion decreased sweating and skin blood flow, and hot pudding ingestion caused marked increases in sweating and vasodilation.

Wimer et al. [49] were the first to examine sweating responses of participants drinking fluids of different temperatures during exercise $\left(2 \mathrm{~h}\right.$ of cycling at $\sim 50 \% \mathrm{VO}_{2-}$ peak). They reported whole-body sweat losses of $471 \mathrm{~g} \cdot \mathrm{h}^{-1}$ with $0.5{ }^{\circ} \mathrm{C}$ water ingestion compared with $679 \mathrm{~g} \cdot \mathrm{h}^{-1}$ with $38^{\circ} \mathrm{C}$ water ingestion of the same volume, as well as parallel changes in blood flow and local sweat rate on the forearm. More recently, our research group reported progressively lower whole-body sweat losses with declining ingested water temperature after $75 \mathrm{~min}$ of exercise at $50 \%$ $V \mathrm{O}_{2 \max }$ in a $24{ }^{\circ} \mathrm{C}$ environment. Sweat losses ranged from $575 \mathrm{~g}$ with the ingestion of $\sim 1 \mathrm{~L}$ of $50{ }^{\circ} \mathrm{C}$ water to $465 \mathrm{~g}$ with the ingestion of the same volume of $1.5{ }^{\circ} \mathrm{C}$ water [50]. From a heat balance perspective, compared with the ingestion of a thermoneutral $\left(37^{\circ} \mathrm{C}\right)$ fluid, the $\sim 140 \mathrm{~kJ}$ of additional internal heat loss in the $1.5{ }^{\circ} \mathrm{C}$ water trial was counterbalanced by an almost proportional $\sim 160 \mathrm{~kJ}$ reduction in potential sweat evaporation from the skin. Similarly, the $\sim 100 \mathrm{~kJ}$ internal heat loss with the ingestion of $10{ }^{\circ} \mathrm{C}$ water was balanced by a $\sim 105 \mathrm{~kJ}$ reduction in evaporative potential from the skin.

To perform further analyses of alterations in human heat balance with cold water ingestion during exercise, the existing literature was searched to capture all studies reporting whole-body sweat losses (to enable the estimation of changes in evaporative potential) following the ingestion of water of at least two different temperatures of a known volume (to enable the estimation of internal heat losses) during steady-state exercise in a non-encapsulated environment. Exercise performance studies were excluded as they employ variable exercise intensities and thus rates of metabolic heat production, which itself would alter sweating independently of ingested fluid temperature [22]. Additionally, studies that did not report whole-body sweat loss values were also excluded as evaporative heat loss could not be estimated [51, 52]. In total, ten studies were included (Table 1), with only three reporting responses with ice slurry ingestion because all other ice slurry studies we found in the literature examined changes in exercise performance. The range of ingested water temperatures represented by the other seven captured studies was from 0.5 to $50{ }^{\circ} \mathrm{C}$ (Table 1$)$.

We estimated differences in evaporative heat loss potential from the skin relative to a control fluid temperature using differences in whole-body sweat losses and the latent heat of vaporisation of sweat $\left(2430 \mathrm{~J} \cdot \mathrm{g}^{-1}\right.$; [35]). We plotted these values (Fig. 3) against parallel differences in internal exchange estimated using fluid volumes administered throughout exercise, change in fluid temperature (core temperature-ingested fluid temperature) and the specific heat capacity of water $\left(4.186 \mathrm{~J} \cdot \mathrm{g}^{-1} \cdot{ }^{\circ} \mathrm{C}^{-1}\right)$ and, if required, the enthalpy of fusion of ice $\left(334 \mathrm{~J} \cdot \mathrm{g}^{-1}\right)$. A strong negative association is evident, that is, as internal heat loss increases with the ingestion of progressively colder fluids, a parallel decrease in evaporative potential from the skin occurs. Indeed, this observation was true for all studiesevidenced by all captured cold water data points falling within the bottom-right quadrant (Fig. 3).

Similarly, the three data points that assessed the relative influence of an internal heat load with the ingestion of a warm fluid resulted in an increase in evaporative potential from the skin supported by elevated sweat rates (top-left quadrant of Fig. 3). As the best-fit regression line for the association does not fall directly along the line of identity, the data indicate that alterations in evaporative potential may not be in direct proportion to changes in internal heat transfer (Fig. 3). That is, reductions in evaporative potential seem to be greater than the increase in internal heat loss with cold water ingestion, and the increase in evaporative potential appears greater than the relatively small amount of internal heat added to the body with warm water ingestion.

This observation however must be viewed with an understanding that methodological approaches for measuring sweat rate differed substantially between studies and the environmental conditions and exercise intensities selected may have induced varying levels of sweating efficiency [41, 43]. Indeed, the additional sweat in the warm fluid conditions may not have actually evaporated; however, in the cool fluid studies/conditions, variations in sweating efficiency do not explain why the reduction in evaporative potential is often disproportionately greater. Moreover, some of the studies included in our analysis did not report significantly different whole-body sweat losses between fluid temperatures, possibly owing to a 
Table 1 Studies reporting sweat losses and core temperature $\left(T_{\mathrm{C}}\right)$ responses during steady-state (fixed-intensity) exercise over a fixed time with ingestion of at least two water temperatures, or one water temperature compared with ice slurry ingestion

\begin{tabular}{|c|c|c|c|c|c|c|c|c|c|}
\hline References, year & $n$ & $\begin{array}{l}T_{\mathrm{a}} \\
\left({ }^{\circ} \mathrm{C}\right)\end{array}$ & $\begin{array}{l}\mathrm{RH} \\
(\%)\end{array}$ & $T_{\text {fluid }}\left({ }^{\circ} \mathrm{C}\right)$ & $\begin{array}{l}\text { End-trial } T_{\mathrm{C}} \\
\left({ }^{\circ} \mathrm{C}\right)\end{array}$ & $\begin{array}{l}\text { Volume } \\
(\mathrm{mL})\end{array}$ & $H_{\text {fluid }}{ }^{\mathrm{a}}(\mathrm{kJ})$ & Sweat loss (g) & $E^{\mathrm{b}}(\mathrm{kJ})$ \\
\hline $\begin{array}{l}\text { Gisolfi and Copping, } \\
1974 \text { [78] }\end{array}$ & 6 & 33.5 & 36 & 10,38 & $39.2,39.4$ & 1200 & 147,1 & 3124,3154 & 7591,7664 \\
\hline Wimer et al., 1997 [49] & 7 & 26 & 40 & $0.5,19,38$ & $38.0,38.0,38.1$ & 1353 & $212,108,1$ & $471,551,649$ & $1144,1339,1571$ \\
\hline $\begin{array}{l}\text { Lee and Shirreffs, } 2007 \\
\text { [25] }\end{array}$ & 9 & 25.4 & 61 & $10,37,50$ & $38.2,38.2,38.3$ & 1000 & $118,5,-49$ & $\begin{array}{l}1230,1260 \\
1320\end{array}$ & $2989,3062,3208$ \\
\hline Lee et al., 2008 [26] & 8 & 25 & 60 & $10,37,50$ & $38.1,38.1,38.2$ & 1200 & $141,6,-59$ & $\begin{array}{l}1090,1230 \\
1350\end{array}$ & $2649,2989,3281$ \\
\hline Bain et al., 2012 [50] & 9 & 23.6 & 23 & $\begin{array}{l}1.5,10,37 \\
50\end{array}$ & $\begin{array}{l}38.0,37.9,38.0, \\
\quad 38.1\end{array}$ & 1030 & $\begin{array}{l}141,104,3 \\
-49\end{array}$ & $\begin{array}{l}465,488,531, \\
575\end{array}$ & $\begin{array}{l}1129,1184,1288, \\
1396\end{array}$ \\
\hline Morris et al., 2014 [55] & 8 & 23.7 & 32 & $1.5,50$ & $37.4,37.4$ & 705 & $106,-37$ & 630,745 & 1530,1810 \\
\hline $\begin{array}{l}\text { Lamarche et al., } 2015 \\
\text { [53] }\end{array}$ & 10 & 25.9 & 25 & $1.5,50$ & $38.0,37.9$ & 1014 & $150,-54$ & 560,634 & 1358,1538 \\
\hline Burdon et al., 2013 [23] & 10 & 32.1 & 40 & Ice, 37 & $38.2,38.3$ & 1560 & 600,8 & 500,600 & 1215,1458 \\
\hline Hailes et al., 2016 [24] & 12 & 35.5 & 50 & Ice, 35.5 & $38.1,38.2$ & $\begin{array}{l}1330, \\
2660\end{array}$ & 511,30 & 2517,2703 & 6116,6568 \\
\hline Morris et al., 2016 [46] & 9 & 33.5 & 24 & Ice, 37 & $37.7,37.7$ & 729 & 201,1 & 568,720 & 1829,2211 \\
\hline
\end{tabular}

$R H$ relative humidity, $T_{a}$ ambient temperature

${ }^{\mathrm{a}}$ Internal heat transfer $\left(H_{\text {fluid }}\right)$ calculated using fluid volume, the specific heat capacity of water $\left(4.186 \mathrm{~J} \cdot \mathrm{g}^{-1} \cdot{ }^{\circ} \mathrm{C}^{-1}\right)$, the enthalpy of fusion of ice (334 J/g) if required and the difference between fluid temperature $\left(T_{\text {fluid }}\right)$ and $T_{\mathrm{C}}$

${ }^{\mathrm{b}}$ Evaporative potential from the skin $(E)$ calculated using sweat loss, the latent heat of vaporisation of sweat (2430 J/g) and assuming $100 \%$ evaporation

Fig. 3 Association between changes in evaporative potential from the skin surface with changes in internal heat loss with ingested fluid/ice. Dotted line indicates line of identity. A best fit line is provided for water ingestion trials only

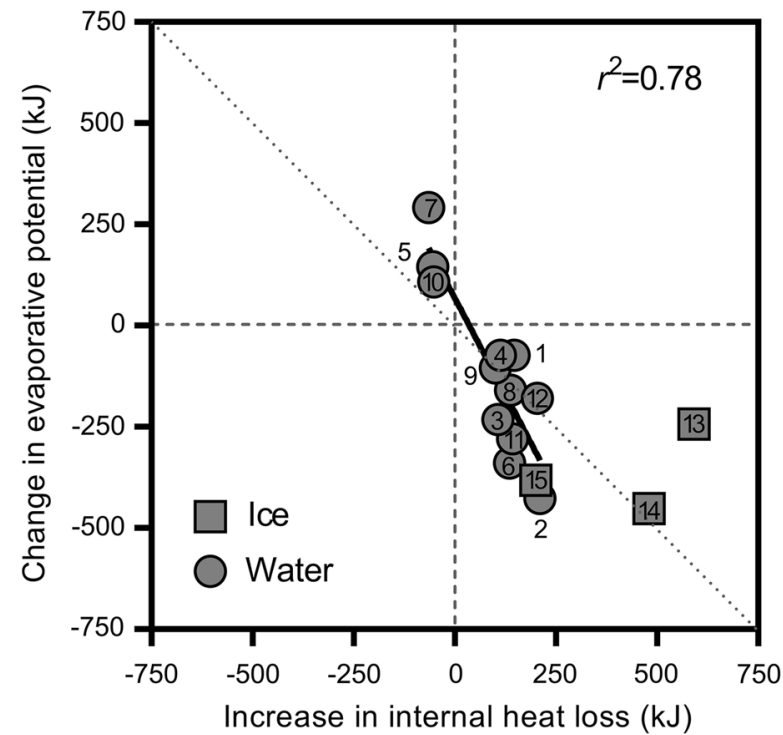

Legend:

1: Gisolfi and Copping $10^{\circ} \mathrm{C}$ [77]

2: Wimer et al. $0.5^{\circ} \mathrm{C}[48]$

3: Wimer et al. $19^{\circ} \mathrm{C}$ [48]

4: Lee and Shirreffs $10^{\circ} \mathrm{C}$ [25]

5: Lee and Shirreffs $50^{\circ} \mathrm{C}$ [25]

6: Lee et al. $10^{\circ} \mathrm{C}[26]$

7: Lee et al. $50^{\circ} \mathrm{C}[26]$

8: Bain et al. $1.5^{\circ} \mathrm{C}$ [49]

9: Bain et al. $10^{\circ} \mathrm{C}$ [49]

10: Bain et al. $50^{\circ} \mathrm{C}$ [49]

11: Morris et al. $1.5^{\circ} \mathrm{C}$ [54]

12: Lamarche et al. $1.5^{\circ} \mathrm{C}[52]$

13: Burdon et al. Ice [23]

14: Hailes et al. Ice [24]

15: Morris et al. Ice [45] combination of relatively small sample sizes and the precision of measurement. Nevertheless, we used mean values reported by all studies.

Lamarche et al. [53] probably provide the most reliable data because they attained the most precise estimates of human heat balance by employing whole-body direct calorimetry. They reported that the $\sim 205 \mathrm{~kJ}$ greater internal heat loss with a $1.5^{\circ} \mathrm{C}$ compared with a $50{ }^{\circ} \mathrm{C}$ water drink was almost fully negated by $\mathrm{a} \sim 180 \mathrm{~kJ}$ reduction in sweat evaporation, with the remaining $\sim 25 \mathrm{~kJ}$ of internal heat loss cancelled by a similar reduction in dry heat loss [53]. Their data also indicate that the disproportionately greater evaporative potential with warm fluid ingestion observed by Bain et al. [50], Lee et al. 
[25] and Lee et al. [26] may have been a function of a reduction in sweating efficiency. Alterations in human heat balance with ice slurry ingestion appear to diverge substantially among the three studies captured by the present analysis. A proportional reduction in evaporative potential [24], as well as disproportionate reduction [46], and a disproportionate maintenance [23] of evaporative potential were all reported.

Irrespective of whether changes in evaporative potential with alterations in internal heat transfer with cold water/ice ingestion are proportional or not, a striking similarity among all captured studies is that at a fixed metabolic heat production any disturbances of heat balance do not deviate sufficiently from the line of identity in Fig. 3 to yield higher or lower core temperatures. Figure 4 illustrates differences in core temperature for all comparisons in Fig. 3 as a function of the difference in internal heat loss and change in evaporative potential. This observation is an essential consideration for athletes exercising in the heat as while they may feel cooler with cold fluid ingestion $[23,28]$, the data indicate that they will not actually be cooler.

It is worth noting that maximum exercise duration among all captured studies was $180 \mathrm{~min}$ [24] and that a longer duration may be required to observe differences in core temperature that arise from an imbalance between internal heat loss and changes in skin surface heat dissipation. Indeed, Senay [54] reported a greater rise in rectal temperature after $12 \mathrm{~h}$ of resting exposure to a $43{ }^{\circ} \mathrm{C}$ environment in participants drinking a fixed volume of cold $\left(8-10{ }^{\circ} \mathrm{C}\right) 0.1 \%$ saline every hour, compared with the same volume and rate of ingestion of thermoneutral $\left(37^{\circ} \mathrm{C}\right)$ $0.1 \%$ saline. Interestingly, reported reductions in evaporative potential in this study, albeit with only three participants, were three to four times greater than the greater internal heat loss with cold saline intake [54].

\subsection{How are Different Sweat Rates Observed Between Fluid Temperatures Without Differences in Core Temperature?}

Rapid but transient fluid temperature-dependent changes in local sweat rates have been observed on the forehead, upper back and arm within 1 min of cold and warm water [55] as well as ice slurry [46] ingestion during exercise. It is well understood that hypothalamic control of sweating is primarily determined by afferent information provided by thermoreceptors in the body core, and to a lesser extent the body shell (i.e. skin) [56-58]. Therefore, the fact that vast differences in skin surface evaporative potential secondary to lower sweat rates are observed alongside similar core (and skin) temperatures implies a modifier of sudomotor control that is sensitive to ingested fluid temperature, and not the action of drinking per se, as changes in sweating are not observed with thermoneutral $\left(37^{\circ} \mathrm{C}\right)$ fluid ingestion $[46,55]$.

A recent study from our laboratory demonstrated that the thermoreceptors responsible most likely reside in, or around, the stomach; mouth-swilling water at 50 and $1.5^{\circ} \mathrm{C}$ had no effect on local sweat rates, whereas directly administering 50 and $1.5^{\circ} \mathrm{C}$ water to the stomach using a nasogatric tube (which bypassed the mouth) elicited

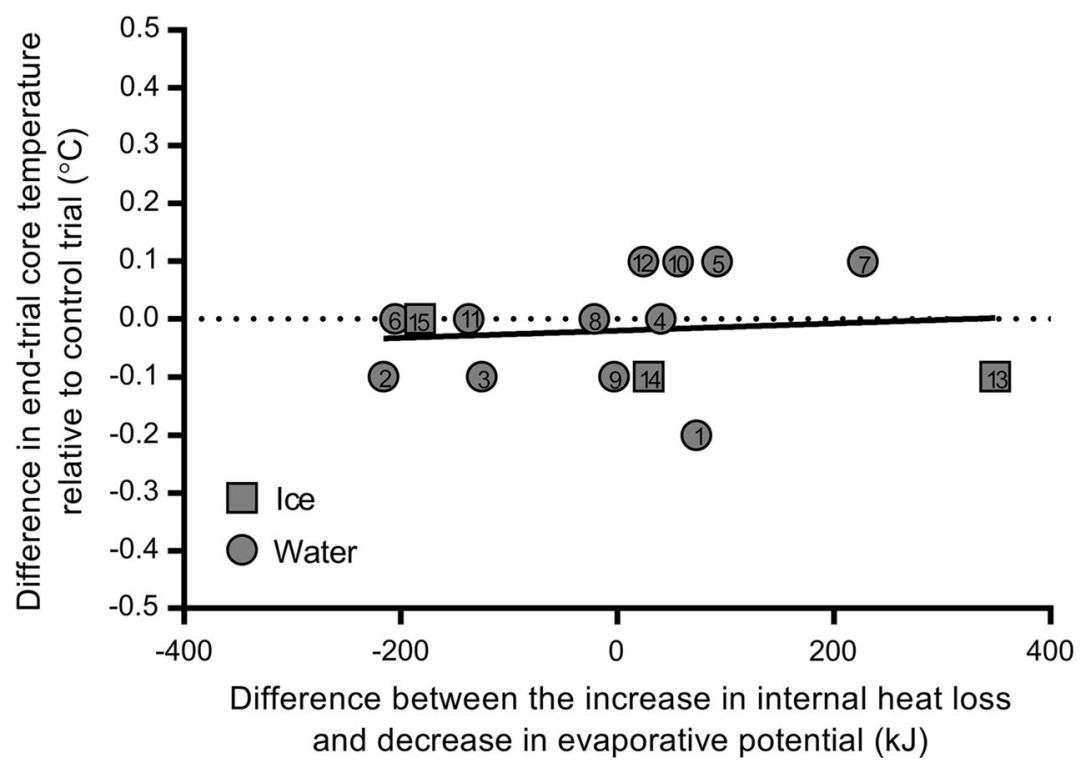

Legend:

1: Gisolfi and Copping $10^{\circ} \mathrm{C}[77]$

2: Wimer et al. $0.5^{\circ} \mathrm{C}[48]$

3: Wimer et al. $19^{\circ} \mathrm{C}$ [48]

4: Lee and Shirreffs $10^{\circ} \mathrm{C}$ [25]

5: Lee and Shirreffs $50^{\circ} \mathrm{C}[25]$

6: Lee et al. $10^{\circ} \mathrm{C}[26]$

7: Lee et al. $50^{\circ} \mathrm{C}[26]$

8: Bain et al. $1.5^{\circ} \mathrm{C}[49]$

9: Bain et al. $10^{\circ} \mathrm{C}[49]$

10: Bain et al. $50^{\circ} \mathrm{C}[49]$

11: Morris et al. $1.5^{\circ} \mathrm{C}[54]$

12: Lamarche et al. $1.5^{\circ} \mathrm{C}$ [52]

13: Burdon et al. Ice [23]

14: Hailes et al. Ice [24]

15: Morris et al. Ice [45]

Fig. 4 Association between the differences in end-trial core temperature relative to control fluid conditions within each study with net differences between internal heat loss and evaporative potential with ingested fluid/ice. A best-fit line is provided for water ingestion trials only 
alterations similar to the water temperature-dependent changes in local sweating with regular drinking [55]. We have since expanded these findings by demonstrating that, similar to cold fluid ingestion, ice slurry ingestion decreases local sweat rate and skin blood flow, but to a greater extent [46]. Most recently, we have also reported an independent influence of cold and warm water ingestion on shivering during cold stress [59].

\subsection{Under What Circumstances Does Cold Water/ Ice Slurry Ingestion Reduce Body Heat Storage?}

\subsubsection{Hot/Humid Environments}

The primary advantage of inducing heat loss internally with cold water or ice slurry ingestion is that heat transfer is guaranteed to be $100 \%$ efficient. In contrast, latent heat dissipation via sweat evaporation is subject to a large variation in efficiency depending on ambient humidity, air velocity across the skin and required sweat rate (dependent upon metabolic heat production). As such, in hot, humid and still climates, reductions in evaporative potential may not result in reductions in actual evaporation; in which case cold water/ice slurry ingestion will be beneficial for reducing body heat storage. It follows that the boundary combinations of air temperature and humidity for different activities (and the accompanying metabolic heat production) at which cold water and ice slurry drinks are beneficial for eliciting a lower heat storage can be estimated. The critical RH above which cold fluids should produce a net cooling effect becomes lower as ambient air temperature increases both for running (Fig. 5a) and cycling (Fig. 5b).

Indeed, in hot and humid conditions, the reduction in sweat output with cold water/ice ingestion does not impact evaporation because additional sweat would only drip off

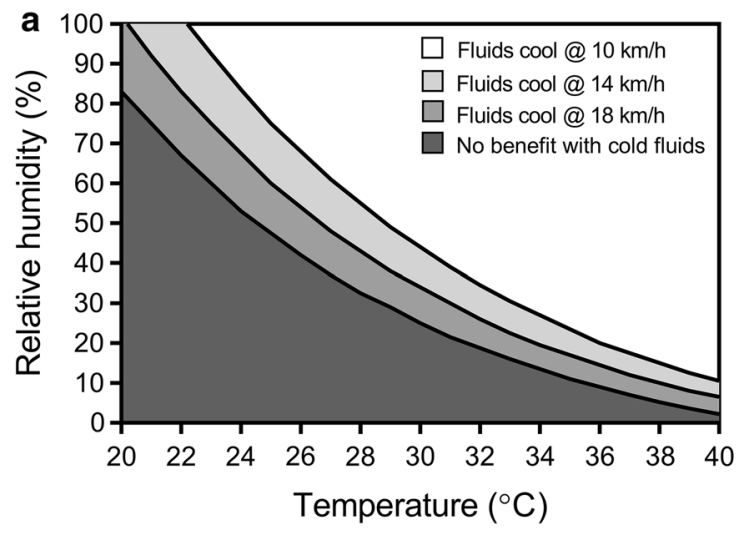

Fig. 5 Estimated environmental boundary conditions at which cold water and ice slurry ingestion provides a net cooling effect for running at 10,14 and $18 \mathrm{~km} / \mathrm{h}$ (a) and cycling on a flat surface at an external power of 180, 240 and $300 \mathrm{~W}$ (b). Rates of metabolic heat production at different running speeds and cycling power outputs the skin and the maximum evaporation possible is attained anyway. Despite a lower air velocity across the skin, a slower runner, notwithstanding differences in running economy, will generate much less heat and therefore much less sweat will be secreted onto the skin resulting in a higher sweating efficiency-under such a scenario, reductions in sweat output would only compromise evaporative heat loss from the skin at higher air temperatures and humidity (Fig. 5a). As a runner travels faster, they must exercise at a higher metabolic heat production, which would result in high sweat rates with a subsequently low proportion of the sweat actually evaporating from the skin; indeed, evaporative efficiency of sweat in heat-acclimated elite athletes has been reported to be well below 50\% [60]. As such, the ambient temperature and RH at which cold fluids would be beneficial in terms of cooling would be drier and cooler for a faster runner (Fig. 5a). For cyclists, ambient airflow across the skin is much higher for a given metabolic heat production when compared with runners, except in the case of steep hill climbing [61]. A high sweating efficiency is therefore maintained at higher air temperatures and humidity for cycling and therefore the boundary conditions for a net cooling effect from cold fluid/ice ingestion are hotter and more humid (Fig. 5b).

\subsubsection{Pre-Cooling}

In contrast to the studies reported earlier in Table 1, in which fluids were administered during exercise, Table 2 contains an aggregate of study findings in which fluids were administered prior to the onset of exercise as a precooling intervention. Here, it is clear that cold fluid or ice ingestion consistently decreases core temperature (by $\sim 0.5^{\circ} \mathrm{C}$ ) before exercise starts. Given that cold fluid ingestion does not seem to be effective for producing a net

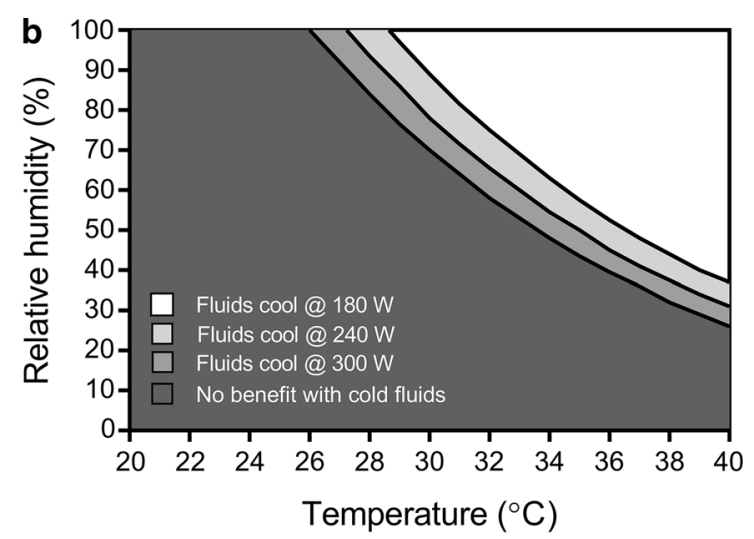

were estimated using standard American College of Sports Medicine equations [79]. Maximum skin wettedness at high air speeds was equal to 0.30 [80]. Boundaries were estimated assuming equivalent reductions in the evaporative heat loss potential from the skin with increases in internal heat loss with cold water/ice ingestion 
Table 2 Aggregate of studies using cold water or ice ingestion as a pre-cooling intervention prior to an exercise performance trial

\begin{tabular}{|c|c|c|c|c|c|c|c|c|c|c|}
\hline References, year & $n$ & $\begin{array}{l}T_{\mathrm{a}} \\
\left({ }^{\circ} \mathrm{C}\right)\end{array}$ & $\begin{array}{l}\mathrm{RH} \\
(\%)\end{array}$ & $\begin{array}{l}T_{\text {fluid }} \\
\left({ }^{\circ} \mathrm{C}\right)\end{array}$ & $\begin{array}{l}T_{\mathrm{C}} \text { at rest } \\
\left({ }^{\circ} \mathrm{C}\right)\end{array}$ & $\begin{array}{l}T_{\mathrm{C}} \text { post- } \\
\text { cooling }\left({ }^{\circ} \mathrm{C}\right)\end{array}$ & $\begin{array}{l}\text { End-trial } T_{\mathrm{C}} \\
\left({ }^{\circ} \mathrm{C}\right)\end{array}$ & $\begin{array}{l}\Delta T_{\mathrm{C}} / \text { time } \\
\left({ }^{\circ} \mathrm{C} \cdot \min ^{-1}\right)\end{array}$ & $\begin{array}{l}\text { Volume } \\
(\mathrm{mL})\end{array}$ & $\begin{array}{l}\text { Sweat rate } \\
\left(\mathrm{g} \cdot \mathrm{h}^{-1}\right)\end{array}$ \\
\hline Lee et al., 2008 [21] & 8 & 35 & 60 & 4,37 & $36.9,36.9$ & $36.4,36.8$ & $39.5,39.5$ & $0.049,0.052$ & 300 & 1220,1400 \\
\hline $\begin{array}{l}\text { Byrne et al., } 2011 \\
\text { [13] }\end{array}$ & 7 & 32 & 60 & 2,37 & $37.3,37.3$ & $36.9,37.1$ & $38.2,38.6$ & $0.043,0.050$ & 900 & 770,980 \\
\hline $\begin{array}{l}\text { Siegel et al., } 2010 \\
\text { [14] }\end{array}$ & 10 & 34 & 55 & Ice, 4 & $37.2,37.1$ & $36.5,36.8$ & $39.4,39.1$ & $0.058,0.057$ & 599 & 1890,2050 \\
\hline $\begin{array}{l}\text { Siegel et al., } 2012 \\
\text { [15] }\end{array}$ & 8 & 34 & 52 & Ice, 37 & $37.1,37.1$ & $36.7,37.1$ & $39.8,39.5$ & $0.059,0.051$ & 586 & 2060,2280 \\
\hline Yeo et al., 2012 [16] & 12 & 28 & 75 & Ice, 31 & $37.5,37.4$ & $37.0,37.3$ & $40.2,39.8$ & $0.071,0.055$ & 511 & 1130,1110 \\
\hline $\begin{array}{l}\text { Naito and Ogaki, } \\
2015[18]\end{array}$ & 9 & 35 & 30 & Ice, 4 & $37.1,37.2$ & $36.8,37.1$ & $38.9,38.9$ & $0.042,0.043$ & 768 & 1800,1700 \\
\hline $\begin{array}{l}\text { Gerrett et al., } 2016 \\
\text { [17] }\end{array}$ & 12 & 31 & 41 & Ice, 23 & $37.3,37.3$ & $36.7,37.3$ & $38.5,38.9$ & $0.058,0.052$ & 551 & 500,510 \\
\hline $\begin{array}{l}\text { Stevens et al., } 2016 \\
\text { [20] }\end{array}$ & 11 & 33 & 46 & Ice, 22 & $37.2,37.2$ & $36.9,37.2$ & $39.0,39.1$ & $0.080,0.073$ & 548 & NA \\
\hline $\begin{array}{l}\text { Naito et al., } 2017 \\
\text { [19] }\end{array}$ & 7 & 35 & 30 & Ice, 4 & $\begin{array}{l}37.1,37.1 \\
37.1\end{array}$ & $\begin{array}{l}36.6,36.7 \\
37.0\end{array}$ & $\begin{array}{l}38.8,38.7 \\
38.6\end{array}$ & $\begin{array}{l}0.048,0.052 \\
0.050\end{array}$ & 530 & $\begin{array}{l}820,1200, \\
720\end{array}$ \\
\hline
\end{tabular}

NA not applicable, $R H$ relative humidity, $T_{a}$ ambient temperature, $T_{c}$ core temperature, $T_{\text {fluid }}$ fluid temperature

cooling effect during exercise because of a compensatory reduction in sweat output and subsequently the evaporative potential from the skin, it stands to reason that if cold fluids are ingested before a full sweating response is developed a reduction in body heat storage will be achieved. Indeed, if the resting core temperature remains within the interthreshold zone, it is defended by neither sweating nor shivering and is allowed to drift with alterations in vasomotor activity solely responsible for slowing the pace of the core temperature change $[62,63]$.

One important caveat of using cold water/ice ingestion as a pre-coolant is that the lower core temperature upon the commencement of exercise most likely delays the onset of sweating, and possibly the vasodilatory response, resulting in a greater rate of heat storage and a greater rate of core temperature rise during the early stages of exercise, as has been demonstrated with whole-body forms of pre-cooling [64]. The data in Table 2 seem to support this proposition as the rate of increase in the core temperature is typically greater with ice slurry ingestion compared with the control fluid (Yeo et al. [16], $+0.016{ }^{\circ} \mathrm{C} \cdot \min ^{-1}$; Siegel et al. [15], $+0.008{ }^{\circ} \mathrm{C} \cdot \mathrm{min}^{-1}$; Stevens et al. [20], $+0.007{ }^{\circ} \mathrm{C} \cdot \mathrm{min}^{-1}$ ) but not always greater (Byrne et al. [13], $\left.-0.007{ }^{\circ} \mathrm{C} \cdot \mathrm{min}^{-1}\right)$.

\subsubsection{Recovery}

While the conditions under which cold fluid/ice ingestion would be beneficial during exercise have been modelled and described (Fig. 5a, b), drinking cold fluids directly after exercise during the early stages of recovery may also successfully create a large net cooling effect. A rapid postexercise decline in sweating and skin blood flow secondary to non-thermal control inputs associated with baroreceptors, mechanoreceptors and metaboreceptors has been well characterised [65] with a $\sim 50 \%$ reduction in sweat output observed within 5 min of stopping exercise despite little (or no) reduction in core temperature [65]. Therefore, from a theoretical perspective, a reduction in sweat output owing to the stimulation of abdominal thermoreceptors from drinking cold fluids or ice post-exercise would have less of an impact on heat storage as sweating is rapidly declining anyway. Such an approach may be particularly relevant for participants in intermittent sports with regular breaks. Few studies have empirically investigated this notion; however, Stanley et al. [30] reported a $\sim 0.4{ }^{\circ} \mathrm{C}$ lower rectal temperature 50-min post-exercise with ice slurry ingestion relative to cold water. Similarly, Lee et al. [29] reported $\mathrm{a} \sim 0.2$ to $0.3^{\circ} \mathrm{C}$ greater decline in core temperature with post-exercise ingestion of $4{ }^{\circ} \mathrm{C}$ water compared with $28{ }^{\circ} \mathrm{C}$ water.

\subsubsection{Clothing}

The boundary environmental conditions presented in Fig. $5 \mathrm{a}, \mathrm{b}$ are for athletes un-encapsulated by protective equipment/clothing and thus able to fully modify skin surface heat loss using physiological heat loss responses. For more encapsulated individuals, skin surface heat loss is less modifiable as only a small proportion of secreted sweat is able to evaporate, with much of the secreted sweat remaining pooled within the clothing microenvironment. 
Athletes competing in sports such as American Football, motorcar racing and fencing are regularly exposed to such scenarios, and cold water or ice slurry ingestion by these individuals will most likely create a large net cooling effect because any reductions in sweating will not greatly impact skin surface evaporation.

While no controlled studies to our knowledge have examined the influence of ingested water temperature/ice in encapsulated athletes, studies examining fire fighters also represent a good occupational surrogate population [66]. In that vein, Pryor and colleagues [67] observed an $\sim 0.5{ }^{\circ} \mathrm{C}$ lower core temperature in fire-fighters ingesting $7.5 \mathrm{~g} / \mathrm{kg}$ total mass of ice slurry mixture prior to exercise in the heat in a complete fire-fighting ensemble, with core temperature remaining lower relative to $20{ }^{\circ} \mathrm{C}$ water ingestion for the first $30 \mathrm{~min}$ of exercise. However, more controlled research studies are required to examine this notion further in encapsulated athletes.

\subsubsection{Physiological Disruptions to Sweating}

From a theoretical perspective, cold fluid or ice slurry ingestion should also be beneficial in populations with a physiological disruption to sweating, such as athletes with a spinal cord injury [68, 69], burn injuries [70-72] or following a sympathectomy procedure [73]. In all situations, the maximum proportion of the skin surface that can be physiologically saturated with sweat (i.e. maximum skin wettedness, $\left.\omega_{\max }\right)$ and the associated maximum level of evaporative heat loss are drastically lowered. The decrease in sweating that accompanies the increase in internal heat loss with a cold/ice drink would therefore have a much smaller impact on heat dissipation and yield an improved net cooling effect compared with an athlete with a completely intact sweating apparatus. While the pre-exercise ingestion of ice slurries has been proven to be moderately effective in reducing core temperature prior to the onset of exercise in wheelchair athletes [68], to the best of our knowledge no existing studies have examined the influence of fluid temperature during exercise in the heat on the development of exercise-induced hyperthermia in these populations.

\section{Note on Different Methods for Estimating Changes in Body Heat Storage During Exercise}

Throughout the present review, we have described and discussed the mutual trade-off between the increase in internal heat transfer with an ingested cold fluid and the parallel reduction in evaporative potential from the skin surface secondary to reductions in sweating - most likely modulated by independent thermoreceptors in the abdominal cavity $[55,59]$. These two heat transfer components have been estimated using well-established [2, 74] fundamental biophysical relationships (partitional calorimetry), and given that concomitant alterations in dry heat transfer via skin surface convection are minimal with cold fluid ingestion [53], they ultimately determine net body heat storage. However, these calculations may in some cases not align with body heat storage values estimated using the thermometric method in some of the studies reported in our review [14, 15, 18, 19, 23, 25, 26]. For example, Lee and Shirreffs [25] estimated body heat storage to be $33 \mathrm{~kJ}$ lower with $10{ }^{\circ} \mathrm{C}$ ingestion compared with $50{ }^{\circ} \mathrm{C}$, yet our estimated difference between the increase in internal heat loss and decrease in skin surface evaporative potential for the same study was $40 \mathrm{~kJ}$ for the $10{ }^{\circ} \mathrm{C}$ fluid and $92 \mathrm{~kJ}$ for the $50{ }^{\circ} \mathrm{C}$ fluid, indicating a $52 \mathrm{~kJ}$ greater potential heat loss with $50{ }^{\circ} \mathrm{C}$ fluid.

The thermometric method for estimating body heat storage (which employs a weighted average of the changes in core and skin temperature together with the mean specific heat capacity of the body's tissues) and total body mass has traditionally been used [75] in many studies captured in this review. However, a series of relatively recent studies has clearly demonstrated, using a reference measure of changes in body heat storage from whole-body direct calorimetry, that values derived using the conventional thermometric approach systematically underestimate the true change in body heat content $[76,77]$. Moreover, this systematic error in heat storage estimation via thermometry is magnified with cold water ingestion to the extent that opposite conclusions can be drawn depending on the method employed [50].

\section{Conclusions and Recommendations}

Cold water and ice slurry ingestion during exercise has been demonstrated to exert a positive influence on endurance performance in the heat. Nevertheless, while cold beverages administered during exercise may help an athlete feel cooler, they do not necessarily result in a net cooling effect owing to a reduction in sweating that lowers the potential for evaporative heat loss from the skin by an amount that is at least equivalent to the additional internal heat loss with the ingested fluid. However, when combinations of activity (metabolic heat production) and climate (air temperature, humidity and airflow) conspire to yield decrements in sweating efficiency (i.e. not all secreted sweat evaporates and thus contributes to cooling), a net cooling effect with cold water/ice ingestion develops, as all internal heat loss is always $100 \%$ efficient. As such, cold water and ice slurry ingestion can be recommended for cooling an athlete during exercise in hot, humid and still 
environments; but not warm, dry and windy environments. In other conditions, athletes should ingest fluids at the temperature they find most palatable and therefore best maintain hydration status.

It follows that generally speaking a cold water/ice ingestion would be more beneficial for cooling runners than cyclists mainly by virtue of the differences in airflow across the skin for a given metabolic heat production and concomitant evaporative efficiency of sweat. Cold water/ ice ingestion should theoretically be more beneficial for athletes with physiological disruptions to sweating capacity, such as spinal cord-injured athletes, as well as athletes wearing equipment/clothing that present a high level of evaporative resistance, e.g. racing car drivers. However, more research is required in these populations.

\section{Compliance with Ethical Standards}

Funding This article was published in a supplement supported by the Gatorade Sports Science Institute (GSSI). The supplement was guest edited by Lawrence L. Spriet who attended a meeting of the GSSI expert panel in October 2016 and received honoraria from the GSSI for his participation in the meeting and the writing of a manuscript. He received no honoraria for guest editing the supplement. Dr. Spriet selected peer reviewers for each paper and managed the process, except for his own paper. Ollie Jay also attended the meeting of the GSSI expert panel in October 2016 and received an honorarium from the GSSI, a division of PepsiCo, Inc. for his meeting participation and the writing of this manuscript. The views expressed in this manuscript are those of the author and do not necessarily reflect the position or policy of PepsiCo, Inc.

Conflict of interest The authors declare that they have no conflicts of interest.

Open Access This article is distributed under the terms of the Creative Commons Attribution 4.0 International License (http:// creativecommons.org/licenses/by/4.0/), which permits unrestricted use, distribution, and reproduction in any medium, provided you give appropriate credit to the original author(s) and the source, provide a link to the Creative Commons license, and indicate if changes were made.

\section{References}

1. Gaesser GA, Brooks GA. Muscular efficiency during steady-rate exercise: effects of speed and work rate. J Appl Physiol. 1975;38:1132-9.

2. Kenny GP, Jay O. Thermometry, calorimetry, and mean body temperature during heat stress. Compr Physiol. 2013;3:1689-719.

3. Nybo L, Rasmussen P, Sawka MN. Performance in the heatphysiological factors of importance for hyperthermia-induced fatigue. Compr Physiol. 2014;4:657-89.

4. Galloway SD, Maughan RJ. Effects of ambient temperature on the capacity to perform prolonged cycle exercise in man. Med Sci Sports Exerc. 1997;29:1240-9.

5. Ely BR, Ely MR, Cheuvront SN, et al. Evidence against a $40{ }^{\circ} \mathrm{C}$ core temperature threshold for fatigue in humans. J Appl Physiol. 2009;107:1519-25.
6. Ruddock A, Robbins B, Tew G, et al. Practical cooling strategies during continuous exercise in hot environments: a systematic review and meta-analysis. Sports Med. 2017;47:517-32.

7. Bongers CCWG, Thijssen DHJ, Veltmeijer MTW, et al. Precooling and percooling (cooling during exercise) both improve performance in the heat: a meta-analytical review. Br J Sports Med. 2015;49:377-84.

8. Duffield R, Green R, Castle P, et al. Precooling can prevent the reduction of self-paced exercise intensity in the heat. Med Sci Sports Exerc. 2010;42:577-84.

9. Minett GM, Duffield R, Marino FE, et al. Volume-dependent response of precooling for intermittent-sprint exercise in the heat. Med Sci Sports Exerc. 2011;43:1760-9.

10. Cotter JD, Sleivert GG, Roberts WS, et al. Effect of pre-cooling, with and without thigh cooling, on strain and endurance exercise performance in the heat. Comp Biochem Physiol A Mol Integr Physiol. 2001;128:667-77.

11. Tyler CJ, Sunderland C. Cooling the neck region during exercise in the heat. J Athl Train. 2011;46:61-8.

12. Sunderland C, Stevens R, Everson B, et al. Neck-cooling improves repeated sprint performance in the heat. Front Physiol. 2015;6:314.

13. Byrne C, Owen C, Cosnefroy A, et al. Self-paced exercise performance in the heat after pre-exercise cold-fluid ingestion. J Athl Train. 2011;46:592-9.

14. Siegel R, Maté J, Brearley $M B$, et al. Ice slurry ingestion increases core temperature capacity and running time in the heat. Med Sci Sports Exerc. 2010;42:717-25.

15. Siegel R, Maté J, Watson G, et al. Pre-cooling with ice slurry ingestion leads to similar run times to exhaustion in the heat as cold water immersion. J Sports Sci. 2012;30:155-65.

16. Yeo ZW, Fan PWP, Nio AQX, et al. Ice slurry on outdoor running performance in heat. Int J Sports Med. 2012;33:859-66.

17. Gerrett N, Jackson S, Yates J, et al. Ice slurry ingestion does not enhance self-paced intermittent exercise in the heat. Scand J Med Sci Sports. 2017;27(11):1202-12.

18. Naito T, Ogaki T. Comparison of the effects of cold water and ice ingestion on endurance cycling capacity in the heat. J Sport Health Sci. 2017;6:111-7.

19. Naito T, Iribe Y, Ogaki T. Ice ingestion with a long rest interval increases the endurance exercise capacity and reduces the core temperature in the heat. J Physiol Anthropol. 2017;36:9.

20. Stevens CJ, Thoseby B, Sculley DV, et al. Running performance and thermal sensation in the heat are improved with menthol mouth rinse but not ice slurry ingestion. Scand J Med Sci Sports. 2016;26:1209-16.

21. Lee JKW, Shirreffs SM, Maughan RJ. Cold drink ingestion improves exercise endurance capacity in the heat. Med Sci Sports Exerc. 2008;40:1637-44.

22. Mündel T, King J, Collacott E, et al. Drink temperature influences fluid intake and endurance capacity in men during exercise in a hot, dry environment. Exp Physiol. 2006;91:925-33.

23. Burdon CA, Hoon MW, Johnson NA, et al. The effect of ice slushy ingestion and mouthwash on thermoregulation and endurance performance in the heat. Int J Sport Nutr Exerc Metab. 2013;23:458-69.

24. Hailes WS, Cuddy JS, Cochrane K, et al. Thermoregulation during extended exercise in the heat: comparisons of fluid volume and temperature. Wilderness Environ Med. 2016;27:386-92.

25. Lee JKW, Shirreffs SM. The influence of drink temperature on thermoregulatory responses during prolonged exercise in a moderate environment. J Sports Sci. 2007;25:975-85.

26. Lee JKW, Maughan RJ, Shirreffs SM. The influence of serial feeding of drinks at different temperatures on thermoregulatory responses during cycling. J Sports Sci. 2008;26:583-90. 
27. Hue O, Monjo R, Riera F. Imposed cold-water ingestion during open water swimming in internationally ranked swimmers. Int $\mathbf{J}$ Sports Med. 2015;36:941-6.

28. Schulze E, Daanen HAM, Levels K, et al. Effect of thermal state and thermal comfort on cycling performance in the heat. Int $\mathrm{J}$ Sports Physiol Perform. 2015;10:655-63.

29. Lee JKW, Yeo ZW, Nio AQX, et al. Cold drink attenuates heat strain during work-rest cycles. Int $\mathrm{J}$ Sports Med. 2013;34:1037-42.

30. Stanley J, Leveritt M, Peake JM. Thermoregulatory responses to ice-slush beverage ingestion and exercise in the heat. Eur J Appl Physiol. 2010;110:1163-73.

31. Williams N, Wickes SJ, Gilmour K, et al. Preparation for and physiological responses to competing in the Marathon des Sables: a case report. J Sports Med Phys Fit. 2014;54:34-42.

32. Gagge AP, Herrington LP, Winslow CEA. Thermal interchanges between the human body and its atmospheric environment. Am J Epidemiol. 1937;26:84-102.

33. Margaria R. Positive and negative work performances and their efficiencies in human locomotion. Int Z Für Angew Physiol Einschließlich Arbeitsphysiologie. 1968;25:339-51.

34. Snellen JW. External work in level and grade walking on a motor-driven treadmill. J Appl Physiol. 1960;15:759-63.

35. Parsons K. Human thermal environments. 2nd ed. New York: Taylor \& Francis Inc; 2003.

36. Ravanelli NM, Jay O. Electric fan use in heat waves: turn on or turn off? Temperature (Austin). 2016;3:358-60.

37. Jay O, Cramer MN, Ravanelli NM, et al. Should electric fans be used during a heat wave? Appl Ergon. 2015;46:137-43.

38. Sawka MN, Young AJ, Latzka WA, et al. Human tolerance to heat strain during exercise: influence of hydration. J Appl Physiol. 1992;73:368-75.

39. Jay O, Brotherhood JR. Occupational heat stress in Australian workplaces. Temperature (Austin). 2016;3:394-411.

40. Gagge AP. A new physiological variable associated with sensible and insensible perspiration. Am J Physiol. 1937;120:277-87.

41. Candas V, Libert JP, Vogt JJ. Influence of air velocity and heat acclimation on human skin wettedness and sweating efficiency. J Appl Physiol. 1979;47:1194-200.

42. Ravanelli N, Coombs G, Imbeault P, Jay O. Maximum skin wettedness following aerobic training with and without heat acclimation. Med Sci Sports Exerc. 2017. https://doi.org/10.1249/ MSS.0000000000001439.

43. Candas V, Libert JP, Vogt JJ. Human skin wettedness and evaporative efficiency of sweating. J Appl Physiol. 1979;46:522-8.

44. Cheung SS, McLellan TM, Tenaglia S. The thermophysiology of uncompensable heat stress. Physiological manipulations and individual characteristics. Sports Med. 2000;29:329-59.

45. Coris EE, Ramirez AM, Durme DJV. Heat illness in athletes. Sports Med. 2004;34:9-16.

46. Morris NB, Coombs G, Jay O. Ice slurry ingestion leads to a lower net heat loss during exercise in the heat. Med Sci Sports Exerc. 2016;48:114-22.

47. Pinson EA, Adolph EF. Heat exchanges during recovery from experimental deficit of body heat. Am J Physiol. 1942;136:105-14.

48. Nadel ER, Horvath SM, Dawson CA, et al. Sensitivity to central and peripheral thermal stimulation in man. J Appl Physiol. 1970;29:603-9.

49. Wimer GS, Lamb DR, Sherman WM, et al. Temperature of ingested water and thermoregulation during moderate-intensity exercise. Can J Appl Physiol. 1997;22:479-93.

50. Bain AR, Lesperance NC, Jay O. Body heat storage during physical activity is lower with hot fluid ingestion under conditions that permit full evaporation. Acta Physiol. 2012;206:98-108.

51. Burdon C, O'Connor H, Gifford J, et al. Effect of drink temperature on core temperature and endurance cycling performance in warm, humid conditions. J Sports Sci. 2010;28:1147-56.

52. Szlyk PC, Sils IV, Francesconi RP, et al. Effects of water temperature and flavoring on voluntary dehydration in men. Physiol Behav. 1989;45:639-47.

53. Lamarche DT, Meade RD, McGinn R, et al. Temperature of ingested water during exercise does not affect body heat storage. Med Sci Sports Exerc. 2015;47:1272-80.

54. Senay LC. Effect of cold dilute saline ingestions on evaporative weight loss of heat-exposed resting men. Proc Soc Exp Biol Med. 1967;124:342-3.

55. Morris NB, Bain AR, Cramer MN, et al. Evidence that transient changes in sudomotor output with cold and warm fluid ingestion are independently modulated by abdominal, but not oral thermoreceptors. J Appl Physiol. 2014;116:1088-95.

56. Nadel ER, Bullard RW, Stolwijk JA. Importance of skin temperature in the regulation of sweating. J Appl Physiol. 1971;31:80-7.

57. Gisolfi CV, Wenger CB. Temperature regulation during exercise: old concepts, new ideas. Exerc Sport Sci Rev. 1984;12:339-72.

58. Simon E, Pierau FK, Taylor DC. Central and peripheral thermal control of effectors in homeothermic temperature regulation. Physiol Rev. 1986;66:235-300.

59. Morris NB, Filingeri D, Halaki M, et al. Evidence of viscerallymediated cold-defence thermoeffector responses in man. J Physiol. 2017;595:1201-12.

60. Malchaire J, Piette A, Kampmann B, et al. Development and validation of the predicted heat strain model. Ann Occup Hyg. 2001;45:123-35.

61. Davison RCR, Swan D, Coleman D, et al. Correlates of simulated hill climb cycling performance. J Sports Sci. 2000;18:105-10.

62. Mekjavic IB, Eiken O. Contribution of thermal and nonthermal factors to the regulation of body temperature in humans. J Appl Physiol. 2006;100:2065-72.

63. Mekjavic IB, Sundberg CJ, Linnarsson D. Core temperature "null zone”. J Appl Physiol. 1991;71:1289-95.

64. Lee DT, Haymes EM. Exercise duration and thermoregulatory responses after whole body precooling. J Appl Physiol. 1995;79:1971-6.

65. Kenny GP, McGinn R. Restoration of thermoregulation after exercise. J Appl Physiol. 2017;122:933-44.

66. McEntire SJ, Suyama J, Hostler D. Mitigation and prevention of exertional heat stress in firefighters: a review of cooling strategies for structural firefighting and hazardous materials responders. Prehospital Emerg Care. 2013;17:241-60.

67. Pryor RR, Suyama J, Guyette FX, et al. The effects of ice slurry ingestion before exertion in Wildland firefighting gear. Prehospital Emerg Care. 2015;19:241-6.

68. Forsyth P, Pumpa K, Knight E, et al. Physiological and perceptual effects of precooling in wheelchair basketball athletes. J Spinal Cord Med. 2016;39:671-8.

69. Griggs KE, Price MJ, Goosey-Tolfrey VL. Cooling athletes with a spinal cord injury. Sports Med. 2015;45:9-21.

70. Crandall CG, Davis SL. Cutaneous vascular and sudomotor responses in human skin grafts. J Appl Physiol. 2010;109:1524-30.

71. Ganio MS, Schlader ZJ, Pearson J, et al. Nongrafted skin area best predicts exercise core temperature responses in burned humans. Med Sci Sports Exerc. 2015;47:2224-32.

72. Ganio MS, Gagnon D, Stapleton J, et al. Effect of human skin grafts on whole-body heat loss during exercise heat stress: a case report. J Burn Care Res. 2013;34:e263-70. 
73. Cramer MN, Jay O. Compensatory hyperhidrosis following thoracic sympathectomy: a biophysical rationale. Am J Physiol. 2012;302:R352-6.

74. Gagge AP, Gonzalez RR. Mechanisms of heat exchange: biophysics and physiology. In: Handbook of physiology, environmental physiology. Bethesda (MD): American Physiological Society; 1996. p. 45-84.

75. Burton AC. Human calorimetry: the average temperature of the tissues of the body. J Nutr. 1935;9:261-80.

76. Jay O, Gariépy LM, Reardon FD, et al. A three-compartment thermometry model for the improved estimation of changes in body heat content. Am J Physiol. 2007;292:R167-75.
77. Jay $\mathrm{O}$, Reardon FD, Webb $\mathrm{P}$, et al. Estimating changes in mean body temperature for humans during exercise using core and skin temperatures is inaccurate even with a correction factor. $\mathrm{J}$ Appl Physiol. 2007;103:443-51.

78. Gisolfi CV, Copping JR. Thermal effects of prolonged treadmill exercise in the heat. Med Sci Sports. 1974;6:108-13.

79. Glass S, Dwyer GB. ACSM'S metabolic calculations handbook. Philadelphia: Lippincott Williams \& Wilkins; 2007.

80. Berglund LG, Gonzalez RR. Evaporation of sweat from sedentary man in humid environments. J Appl Physiol. 1977;42:767-72. 